Quim. Nova, Vol. 33, No. 4, 816-820, 2010

\title{
INFLUENCE OF Ni ADDITION TO A LOW-LOADED PALLADIUM CATALYST ON THE SELECTIVE HYDROGENATION OF 1-HEPTYNE
}

\author{
Cecilia R. Lederhos*, Juan M. Badano, Mónica E. Quiroga e Pablo C. L’Argentière \\ Instituto de Investigaciones en Catálisis y Petroquímica / Facultad de Ingeniería Química, Universidad Nacional del Litoral, \\ Santiago del Estero 2654, 3000 Santa Fe, Argentina \\ Fernando Coloma-Pascual \\ Servicios Técnicos de Investigación, Facultad de Ciencias, Universidad de Alicante, Apartado 99, E-03080 Alicante, Spain
}

Recebido em 27/4/09; aceito em 30/10/09; publicado na web em 12/3/10

\begin{abstract}
Semi-hydrogenation of alkynes has industrial and academic relevance on a large scale. To increase the activity, selectivity and lifetime of monometallic catalysts, the development of bimetallic catalysts has been investigated. 1-Heptyne hydrogenation over low-loaded Pd and Ni monometallic and PdNi bimetallic catalysts was studied in liquid phase at mild conditions. XPS results suggest that nickel addition to Pd modifies the electronic state of palladium as nickel loading is increased. Low-loaded Pd catalysts showed the highest selectivities (>95\%). The most active prepared catalyst, $\mathrm{PdNi}_{(1 \%)}$, was more selective than the Lindlar catalyst.
\end{abstract}

Keywords: bimetallic catalysts; alkyne; Lindlar.

\section{INTRODUCTION}

Petroleum cuts contain mixtures of unsaturated and aromatic compounds. Acetylenic hydrocarbons are very unstable; by selective hydrogenation at mild conditions these compounds may be transformed to olefinic compounds. Alkenes have industrial and academic relevance on a large scale; industries such as petrochemical, pharmaceutical and agrochemical use these compounds as raw materials. ${ }^{1}$ Semi-hydrogenation reactions allow a reduction in operational costs and also enable high selectivities to alkenes.

Classical heterogeneous catalysts for carbon-carbon multiple bond hydrogenation contain noble metals such as $\mathrm{Pd}, \mathrm{Pt}, \mathrm{Ru}, \mathrm{Rh}$, which are highly active and selective. ${ }^{2}$ Many authors have found that supported palladium catalysts present the highest catalytic activity for the semihydrogenation of alkynes to alkenes. ${ }^{3,4}$ The typical commercial catalyst used since 1952 for selective hydrogenation of alkynes is the Lindlar catalyst, that contains palladium poisoned with lead $\left(\mathrm{Pd} / \mathrm{CaCO}_{3}, 5 \%\right.$ $\mathrm{Pd}$ modified with $\left.\mathrm{Pb}(\mathrm{OAc})_{2}\right) .{ }^{5}$ In the last decade the cost of this noble metal has increased greatly and the world tendency is to develop cheaper catalysts by reducing the Pd content and by using cheaper metals. The use of low cost metals, such as $\mathrm{Ni}$, has been studied, for example, for the semi-hydrogenation of alkynes. Partially reduced Ni-Al mixed oxide $^{6}$ or nickel nanoparticles ${ }^{7,8}$ are some of the catalysts thus tried. Alonso et al..$^{7}$ developed a mild and simple methodology for efficient stereoselective semi-hydrogenation of alkynes based on both in situ generated $\mathrm{Ni}(0)$ nanoparticles and $\mathrm{H}_{2}$. Recently, Dhakshinamoorthy and Pitchumani ${ }^{8}$ found that nickel nanoparticles entrapped in a clay matrix ( $2.84 \mathrm{wt} \% \mathrm{Ni}$ ) exhibited good activity for the reduction of a wide range of substrates, in the absence of an external hydrogen source. Zhao et al. ${ }^{9}$ prepared a nano-nickel catalyst modified by ruthenium for hydrogenation and hydrodechlorination; the NiRu catalyst exhibited a higher selectivity than the Ni catalyst. This was attributed to an interation between $\mathrm{Ni}$ and $\mathrm{Ru}$ : Ni transferred electrons to Ru. Choi and Yoon ${ }^{10}$ also found low activities and selectivities when using nickel boride catalysts for the selective hydrogenation of non terminal alkynes.

To increase the activity and/or the selectivity and lifetime of monometallic catalysts in many hydrogenation reactions, some authors have

*e-mail: clederhos@ fiq.unl.edu.ar prepared bimetallic catalysts. The use of $\mathrm{Ni}, \mathrm{Ag}, \mathrm{Au}, \mathrm{Ge}, \mathrm{Sn}, \mathrm{Pb}$ as second metals added to supported palladium catalysts has been studied. ${ }^{11-14}$ The major part of these studies has used bimetallic catalysts for the semi-hydrogenation of short chain alkynes. ${ }^{11-13,15}$ There are fewer papers dealing with the selective hydrogenation of long chain terminal alkynes. ${ }^{16}$ To increase the selectivity to the alkene, milder conditions of hydrogen pressure and temperature are normally used. ${ }^{3}$

In previous papers ${ }^{17}$ we have studied the semi-hydrogenation of a long chain alkyne (1-heptyne) using high-loaded Pd and Ru supported catalysts. The influence of different supports (alumina and an activated carbon) as well as reaction and reduction temperatures, were analyzed in those papers.

The objective of this paper is to obtain low-loaded $\mathrm{Pd}$ and $\mathrm{Ni}$ monometallic and Pd-Ni bimetallic catalysts, and to study the influence of the nickel content on the activity and selectivity of the bimetallic catalysts during the semi-hydrogenation of 1-heptyne, a high molecular weight terminal alkyne.

\section{EXPERIMENTAL}

\section{Catalyst preparation}

All of the catalysts were prepared using $\gamma-\mathrm{Al}_{2} \mathrm{O}_{3}$ Ketjen $\mathrm{CK}$ $300\left(\mathrm{~S}_{\mathrm{BET}}: 180 \mathrm{~m}^{2} \mathrm{~g}^{-1}\right.$, cylinders of $1.5 \mathrm{~mm}$ diameter) as support. Monometallic catalysts were impregnated by the incipient wetness technique with aqueous solutions of $\mathrm{Pd}\left(\mathrm{NO}_{3}\right)_{2}$ (Fluka, Cat. $\mathrm{N}^{\mathrm{o}} 76070$ ) and $\mathrm{Ni}\left(\mathrm{NO}_{3}\right)_{2} \cdot 6 \mathrm{H}_{2} \mathrm{O}$ (Fluka, Cat. $\mathrm{N}^{\mathrm{o}} 72253$ ) at $\mathrm{pH}=1$ with $\mathrm{HNO}_{3}$ solution, in concentrations such as to obtain $0.4 \mathrm{Pd}$ wt \% (PdAl catalyst) and $1 \mathrm{Ni}$ wt \% (NiAl catalyst), respectively, on the final catalysts. The samples were dried overnight at $373 \mathrm{~K}$ and calcined at $773 \mathrm{~K}$ for $3 \mathrm{~h}$. Then bimetallic catalysts were prepared from the palladium monometallic catalyst by successive impregnation using a $\mathrm{Ni}\left(\mathrm{NO}_{3}\right)_{2} \cdot 6 \mathrm{H}_{2} \mathrm{O}(\mathrm{pH}=1)$ aqueous solution in order to achieve 1.0 and $0.5 \mathrm{wt} \% \mathrm{Ni}$ loadings ( $\mathrm{Pd}-\mathrm{Ni}_{(1.0 \%)}$ and $\mathrm{Pd}-\mathrm{Ni}_{(0.5 \%)}$ catalysts) in the final bimetallic catalysts. All the catalysts were finally calcined at $623 \mathrm{~K}$ for $3 \mathrm{~h}$ and reduced under a hydrogen stream at $673 \mathrm{~K}$ for $1 \mathrm{~h}$, except the palladium monometallic catalyst, which was reduced at $573 \mathrm{~K}$ for $1 \mathrm{~h}$. All the catalysts were immediately used in the test reaction after the reduction treatment. 
A commercial Lindlar catalyst in powder form was provided by Aldrich (Cat. No 20 573-7, 5\% Pd on calcium carbonate, poisoned with lead) and used for comparative purposes.

\section{Catalyst characterization}

The metal loading of the mono and bimetallic catalysts was determined by spectrophotometric analysis, previous digestion of the samples, ${ }^{18}$ in a Metrolab 1700 UV-VIS equipment. Dispersion values were obtained by hydrogen chemisorption in a Micromeritics Accusorb 2100 e equipment at 373 K. $0.2 \mathrm{~g}$ samples were first reduced in situ in the presence of a hydrogen stream, then chemisorption was performed using the method proposed by Benson et al. ${ }^{19}$ An atomic ratio $\mathrm{H}: \mathrm{M}$ equal to 1 was used for all of the calculations..$^{20-22}$

The electronic state of the surface superficial species and their atomic ratios were determined by X-ray Photoelectron Spectroscopy (XPS). Measurements were acquired in a VG-Microtech Multilab equipment with a $\mathrm{MgK}_{\alpha}(\mathrm{hv}: 1253.6 \mathrm{eV}$ ) radiation source and a pass energy of $50 \mathrm{eV}$. The analysis pressure during data acquisition was kept at $5 \cdot 10^{-7} \mathrm{~Pa}$. Samples were treated in situ in the presence of a $\mathrm{H}_{2}$ stream following the same pretreatment conditions for each catalyst. A careful deconvolution of the spectra was made and the areas of the peaks were estimated by calculating the integral of each peak after subtracting a Shirley background and fitting the experimental peak to a combination of Lorentzian/Gaussian lines of 30-70\% proportions. The reference binding energy (BE) was $\mathrm{C} 1 \mathrm{~s}$ peak at 285.0 $\mathrm{eV}$. Determinations of the superficial atomic ratios were made by comparing the areas under the peaks after background subtraction and corrections due to differences in escape depth and in photoionization cross sections. ${ }^{23}$

Temperature Programmed Reduction (TPR) measurements were carried out in a Micromeritics Auto Chem II instrument equipped with a thermal conductivity detector. The calcined samples were treated at $373 \mathrm{~K}$ for $30 \mathrm{~min}$ under an argon stream in order to eliminate humidity. Then the samples were cooled down to $200 \mathrm{~K}$ in the same atmosphere, and then they were heated up to $723 \mathrm{~K}$ at $10 \mathrm{~K} \mathrm{~min}^{-1}$ in a $5 \%(\mathrm{v} / \mathrm{v})$ hydrogen/argon mixture stream.

\section{Catalytic test reaction}

1-Heptyne selective hydrogenation was performed in a batch stainless steel stirred tank reactor equipped with a magnetically driven stirrer with two blades in counter-rotation, which was operated at $750 \mathrm{rpm}$. The inner wall of the reactor was completely coated with PTFE in order to neglect the catalytic action of the steel of the reactor found by other authors. ${ }^{24}$ Catalytic tests were carried out in triplicate with an experimental error of $3 \%$. The reaction was carried out at $303 \mathrm{~K}$ and $150 \mathrm{kPa}$ of $\mathrm{H}_{2}$ pressure using $0.75 \mathrm{~g}$ of catalyst in a total volume of $75 \mathrm{~mL}$. A $5 \%(\mathrm{v} / \mathrm{v})$ solution of 1-heptyne (Fluka, Cat. $\mathrm{N}^{\circ}$ 51950) in toluene (Merck, Cat. $\mathrm{N}^{\circ}$ TX0735-44) was used as feed. The reactant:palladium molar ratio used was 1100 for the palladium mono and bimetallic catalysts and for the Lindlar catalyst, and the reactant:nickel used for NiAl was 170 .

The possibility of diffusional limitations during the catalytic tests was investigated following procedures previously described. ${ }^{25}$ Experiments were carried out at different stirring velocities in the 180-1400 rpm range. The constancy of the activity and selectivity above 500 rpm ensured that external diffusional limitations were absent at the rotary speed selected $(750 \mathrm{rpm})$. To ensure that the catalytic results were not influenced by intra-particle mass transfer limitations, the catalyst particles were crushed up to $1 / 4$ of their original size. Then, several runs using the crushed catalysts were carried out. In every case, the conversion and selectivity values obtained were the same than those corresponding to the catalyst that was not crushed. Hence, it can be accepted that internal diffusional limitations were absent in the operational conditions of this work.

Reactant and products were analyzed by gas chromatography using a flame ionization detector and a HP INNOWax Polyetilenglycol capillary column. The only compounds detected by GC were 1-heptyne, 1-heptene and n-heptane.

Activity results were expressed as Turn Over Frequencies (TOF), calculated from the initial values of the conversion vs. time curves, assuming a zero order reaction kinetics with respect to the alkyne. ${ }^{26}$

\section{RESULTS AND DISCUSSION}

Table 1 shows the values of metal loading (\%), dispersion (\%), reduction degree $(\%)$ of the metals as determined by TPR, binding energy (BE) of the $\mathrm{Pd} 3 \mathrm{~d}_{5 / 2}$ peak and $\mathrm{Ni} / \mathrm{Pd}$ atomic ratios as obtained by XPS for all of the catalysts studied. The activity values expressed as TOF $\left(\mathrm{s}^{-1}\right)$ are also included in this table.

Table 1. Metal loading (\%), dispersion (D), reduction degree (\%), initial activity (TOF) and XPS results for PdAl, NiAl, Pd-Ni catalysts and Lindlar catalyst

\begin{tabular}{lcccccccc}
\hline & \multicolumn{3}{c}{ Metal loading } & \multicolumn{3}{c}{ Reduction Degree } & \multicolumn{3}{c}{ XPS } \\
Catalysts & $\begin{array}{c}\mathrm{Pd} \\
(\mathrm{wt} \%)\end{array}$ & $\begin{array}{c}\mathrm{Ni} \\
(\mathrm{wt} \%)\end{array}$ & $\begin{array}{c}\mathrm{D} \\
(\%)\end{array}$ & $\begin{array}{c}\mathrm{Pd} \\
(\%)\end{array}$ & $\begin{array}{c}\mathrm{Ni} \\
(\%)\end{array}$ & $\begin{array}{c}\mathrm{TOF} \\
\left(\mathrm{s}^{-1}\right)\end{array}$ & $\begin{array}{c}\mathrm{Pd} 3 \mathrm{~d}_{5 / 2} \\
\mathrm{BE}(\mathrm{eV})\end{array}$ & $\begin{array}{l}\mathrm{Ni} / \mathrm{Pd} \\
(\%)\end{array}$ \\
\hline PdAl & 0.37 & -- & 32 & 96 & -- & 0.10 & 334.9 & -- \\
Pd-Ni $_{(0.5 \%)}$ & 0.37 & 0.46 & 29 & 92 & 18 & 0.15 & 335.6 & 1.8 \\
Pd-Ni $_{(1.0 \%)}$ & 0.37 & 0.89 & 31 & 74 & 7 & 0.16 & 335.9 & 3.0 \\
NiAl & -- & 1.29 & 3 & -- & 16 & 1.12 & -- & -- \\
Lindlar & 5 & -- & 2.5 & -- & -- & 1.94 & 337.2 & -- \\
\hline
\end{tabular}

The dispersion results showed in Table 1 indicate that the addition of nickel to the palladium monometallic catalyst does not modify its metallic dispersion. The dispersion values obtained are also coincident with those previously reported. ${ }^{27}$

As it can be seen in Table 1 the XPS results for the palladium monometallic catalyst treated in hydrogen at $573 \mathrm{~K}$ show that the $\mathrm{Pd}$ $3 \mathrm{~d}_{5 / 2}$ signal is located at $334.9 \mathrm{eV}$; according to the literature, it can be assigned to $\mathrm{Pd}^{\circ} .^{24,28,29}$ For the nickel monometallic catalyst reduced at $673 \mathrm{~K}$, the $\mathrm{BE}$ for $\mathrm{Ni} 2 \mathrm{p}_{3 / 2}$ was $853.5 \mathrm{eV}$, which can be assigned to electro-defficient nickel species $\left(\mathrm{Ni}^{\mathrm{n}+}\right)$, probably corresponding to nickel interacting with aluminum. ${ }^{30}$ The $\mathrm{BE}$ of the $\mathrm{Pd} 3 \mathrm{~d}_{5 / 2}$ signal in the bimetallic catalyst increases with the nickel content: 335.6 and 335.9 $\mathrm{eV}$ for 0.5 and $1.0 \mathrm{Ni}$ wt \%, respectively (see in Table 1). According to the literature, these values correspond to electron-deficient palladium ( $\mathrm{Pd}^{\mathrm{n}}$, with $n+$ between 0 and 2$){ }^{28,31}$ As previously reported, ${ }^{27}$ AES and XPS studies show that nickel addition as a second metal to Pd catalysts modifies the electronic state of palladium leaving it more electron-deficient as nickel loading is increased. Table 1 also shows that the superficial atomic ratio Ni/Pd increased as the nickel loading was raised. The $\mathrm{Pd} 3 \mathrm{~d}_{5 / 2}$ peak $\mathrm{BE}$ in the Lindlar catalyst was $337.2 \mathrm{eV}$ indicating that palladium is present as an electron-deficient species $\left(\mathrm{Pd}^{\mathrm{n}+}\right)$.

Figure 1 shows the TPR profiles of mono and bimetallic catalysts. The palladium monometallic catalyst (Figure 1a) presents a main peak at low temperature $(287 \mathrm{~K})$, that according to the literature ${ }^{12,21,32,33}$ could be attributed to the reduction of $\mathrm{PdO}$ particles to metallic palladium. This profile also shows an inverted peak at $339 \mathrm{~K}$ which could be assigned to the decomposition of the $\beta$-PdH phase. ${ }^{12,21,29,32,34}$ This proves that at the reduction temperature adopted for the $\mathrm{PdAl}$ catalyst $(573 \mathrm{~K})$ the palladium $\beta$-hydride phase was eliminated.

The TPR profile of the Ni monometallic catalyst in Figure $1 \mathrm{~b}$ shows a main peak of Ni reduction at c.a. $600 \mathrm{~K}$ that can be attribu- 


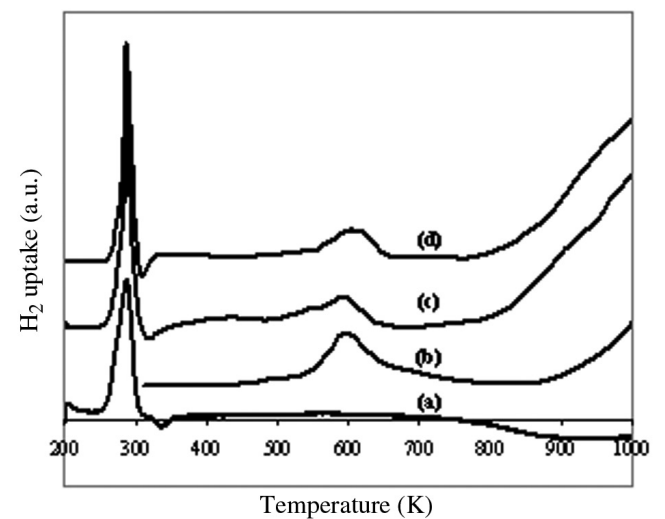

Figure 1. TPR traces of $\mathrm{PdAl}(\mathrm{a}), \mathrm{NiAl}(\mathrm{b})$ and bimetallic catalysts: $P d-N i_{(0.5 \%)}$ (c) and $\mathrm{Pd}-\mathrm{Ni} i_{(1.0 \%)}(d)$

ted to $\mathrm{NiO}$ species with a weak metal-support interaction. ${ }^{35-39}$ It is well known that nickel monometallic catalysts prepared from nitrate salts are reduced at temperatures between 600 to $1000 \mathrm{~K}$ when the contact between $\mathrm{NiO}$ and alumina is intimate..$^{6,36,38,39}$ The patterns of reduction depend on the nature of the metal-support interactions, which can be modified by the calcination temperature employed during the preparation of the monometallic nickel catalysts. ${ }^{6}$ Hence the hydrogen consumption can be attributed to the reduction of $\mathrm{NiO}$ species with a weak interaction with the support. This is in agreement with the XPS results.

The TPR profiles of the bimetallic catalysts are presented in Figures $1 \mathrm{c}$ and $1 \mathrm{~d}$. Up to $500 \mathrm{~K}$ the bimetallic reduction profiles are very similar to those corresponding to those of monometallic $\mathrm{Pd}$. The TPR profiles of $\mathrm{Pd}-\mathrm{Ni}_{(0.5 \%)}$ and $\mathrm{Pd}-\mathrm{Ni}_{(1.0 \%)}$ have their main peaks at 287 or $286 \mathrm{~K}$, respectively, corresponding to $\mathrm{PdO}$ reduction, as was determined for the monometallic PdAl catalyst. However, these signals corresponding to the bimetallic catalysts are narrower than that corresponding to the monometallic one. The decomposition peak for the $\beta$-PdH phase was also present in the bimetallic catalysts at 316 or $307 \mathrm{~K}$ when 0.5 or $1.0 \mathrm{wt} \%$ of $\mathrm{Ni}$ was added as a second metal. The shifts of the signals of the bimetallic catalysts to lower temperatures show that the decomposition of the $\beta$-PdH phase is more easily accomplished when nickel loading is increased. The reduction temperature adopted for Pd bimetallic catalysts $(673 \mathrm{~K})$ ensures the elimination of the $\beta$-PdH phase. Furthermore, as showed in Figures 1c and 1d, the bimetallic catalysts with 0.5 and $1.0 \mathrm{Ni}$ wt \% have peaks at 598 and $621 \mathrm{~K}$, respectively, due to the reduction of $\mathrm{NiO}$ species to $\mathrm{Ni}^{\mathrm{o}} .^{38-40}$ The position of these peaks is slightly modified as the $\mathrm{Ni}$ loading is increased. A similar behavior was observed by other authors when studying Ni monometallic catalysts. ${ }^{37}$ More work is necessary to get a better insight on this problem.

According to the results of degree of reduction of Table 1 the Pd$\mathrm{Ni}_{(1.0 \%)}$ catalyst had the lowest percentage of reduced $\mathrm{Ni}$ and $\mathrm{Pd}$. This suggests the presence of a stronger Pd-Ni interaction in this catalyst than in the other bimetallic catalysts. However, the interaction of Pd and $\mathrm{Ni}$ with the support cannot be neglected.

Figure 2 shows the selectivity to 1-heptene (\%) as a function of time for the monometallic and bimetallic catalysts. It can be observed that, except for the supported nickel catalyst, all the other catalysts have excellent selectivities to 1-heptene, the desired product, with values higher than $97 \%$. It can also be seen that the selectivity was high and constant (c.a. 98\%) and it is not affected by the nickel content. Therefore it can be said that the addition of $\mathrm{Ni}$ as a second metal to the alumina supported palladium catalysts has no influence on the selectivity to 1 -heptene. The nickel monometallic catalyst

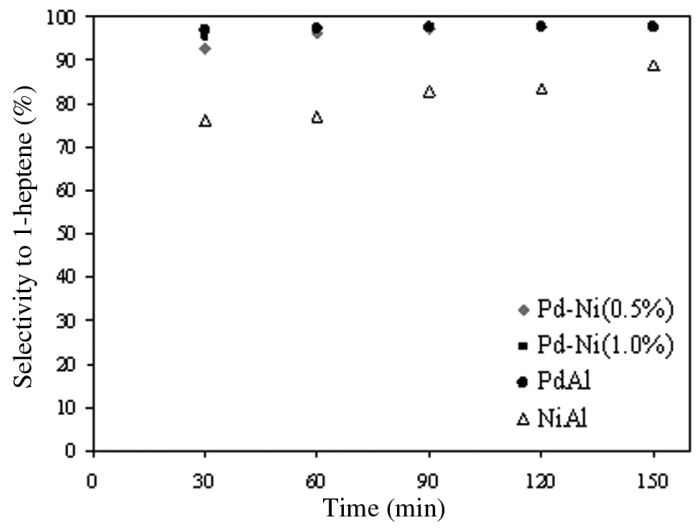

Figure 2. Selectivity to 1-heptene (\%) vs. time (min) for monometallics: PdAl $(\bullet), N i A l(\Delta)$ and bimetallics: $P d-N i_{(0.5 \%)}(\bullet)$ and $P d-N i_{(1.0 \%)}(\mathbf{\square})$

had the lowest selectivity values (between 76 and 91\%) as it can be seen in Figure 2.

Figure 3 shows the total conversion of 1-heptyne (\%) as a function of time for the mono and bimetallic catalysts studied. It can be clearly seen that the nickel addition to the palladium monometallic catalyst rises the total conversion; the increment of the nickel content leads to higher total conversion values. However, the supported nickel monometallic catalyst shows a considerable higher total conversion than that obtained with the palladium monometallic catalyst and also with the bimetallic catalysts, although it is the less selective system.

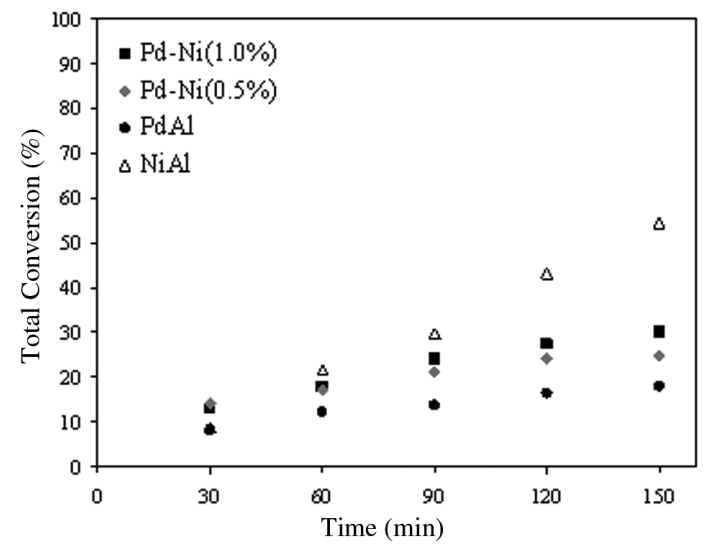

Figure 3. Total conversion (\%) vs. time ( $\mathrm{min})$ for monometallics: PdAl (•), $\mathrm{NiAl}(\Delta)$ and bimetallics: $\mathrm{Pd}-\mathrm{Ni} i_{(0.5 \%)}(\bullet)$ and $\mathrm{Pd}-\mathrm{Ni} i_{(1.0 \%)}(\mathbf{\square})$

Values of total conversion (\%) and selectivity to 1-heptene (\%) as a function of time are shown in Figure 4 for the Lindlar catalyst. This reference catalyst shows a relatively high selectivity to the desired product (c.a. 87\%), although lower than that obtained with the palladium mono and bimetallic catalysts (c.a. 98\%). The 1-heptyne total conversion values obtained with the commercial Lindlar catalyst are higher than those obtained with the Pd-Ni catalysts at 120 min reaction time, although its selectivity decreases markedly. As previously mentioned the Lindlar catalyst contains electrondeficient palladium species. Nijhuis et al. ${ }^{41}$ have found that palladium modified with $\mathrm{Pb}(\mathrm{OAc})_{2}$ during the Lindlar catalyst preparation gets electron deficient and that this electron deficiency enhances the Pd-alkyne interaction. It should be also considered that 1-heptene is adsorbed more weakly than 1-heptyne on these species. Hence, once formed, 1-heptene molecules are more easily desorbed than the alkyne molecules.

Figure 5 compares the selectivity to 1-heptene as a function of the total conversion for all of the catalysts. It can be seen that up to 


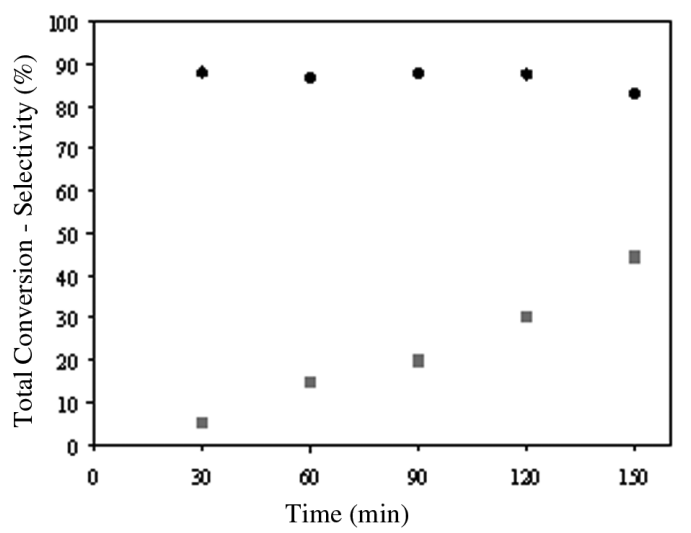

Figure 4. Total conversion (\%) (ロ) and selectivity to 1-heptene (\%) (•) vs. time ( $\mathrm{min})$ for the Lindlar catalyst

a value of $30 \%$ of 1 -heptyne total conversion, the Pd-Ni bimetallic catalysts and the Pd monometallic catalyst are more selective than the Lindlar catalyst. The lowest values in selectivity to 1-heptene, in the whole evaluated conversion range, are those of the nickel monometallic catalyst.

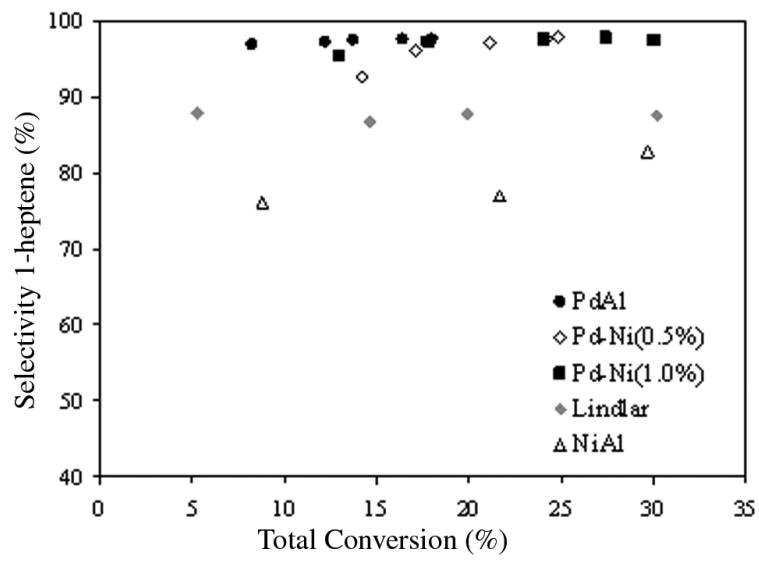

Figure 5. Selectivity to 1-heptene (\%) vs. total conversion (\%) for PdAl (•), $P d-N i_{(0.5 \%)}(\diamond), P d-N i_{(1.0 \%)}(\bullet)$, Lindlar catalyst $(\bullet)$ and $\mathrm{NiAl}(\Delta)$

From the TOF values displayed in Table 1 it may be concluded that the mono and bimetallic Pd catalysts have moderate activities, similar among them. It can be seen in Table 1 that the activity of the palladium catalysts increased slightly with nickel loading. The Lindlar catalyst is the most active one.

Coq and Figueras ${ }^{42}$ concluded, after analyzing a wide number of papers on the matter of_palladium bimetallic catalysts, that the disappearing of the $\beta$ - $\mathrm{PdH}$ phase plays an important role on the activity and selectivity of the reactions. These authors state that the disappearance of the $\beta$ - $\mathrm{PdH}$ phase considerably decreases the alkynes hydrogenation rate to alkanes, thus increasing the selectivity to alkenes. It is well known that in the case of alkyne hydrogenations on supported Pd catalysts, the $\beta$-hydride phase may act as a hydrogen source that promotes overhydrogenation, with a consequent decrease in the selectivity to alkene formation. ${ }^{43}$ Hence the high selectivities obtained with our Pd mono and bimetallic catalysts could be attributed, at least in part, to the disappearance of the $\beta$-PdH phase. From academic and industrial points of view the achievement of high selectivity values of the desired products is the most appreciated characteristic of any catalyst.

There is not a simple interpretation to explain the influence of the second metal on the Pd performance. The alkynes semi-hydrogenation reactions are more or less sensitive to geometrical and electronic effects, being the latter the most important ones. The properties of palladium based bimetallic catalysts are related to the preparation method, which affects the electronic and chemical state of Pd and of the second metal, as well as their spatial distribution. The $\mathrm{Pd}^{\mathrm{n}+}$ species are weak electron donors as compared to $\mathrm{Pd}^{\circ}$ species. This modification of the electronic state of palladium could be responsible for the better catalytic behavior, moreover considering the high electronic density of the triple bond. As observed by XPS, the nickel addition to the palladium catalyst promoted the electron deficiency of Pd. The higher the nickel content, the higher the palladium electron deficiency. However, the influence of geometrical effects and/or mixed sites on the activity of bimetallic catalysts can not be discarded.

The most active prepared catalyst was $\mathrm{Pd}-\mathrm{Ni}_{(1.0 \%)}$, which resulted much more selective than the Lindlar catalyst. Also the $\mathrm{Pd}-\mathrm{Ni}_{(1.0 \%)}$ was more active than the monometallic Pd catalyst which indicates a positive synergetic effect of Ni over Pd. Besides, this bimetallic catalyst presents another advantages, which are the low Pd loading $(0.4 \mathrm{wt} \%)$ and the low cost of the nickel precursor. Moreover, the Lindlar catalyst has the disadvantage that it cannot be pelletized and must be operated under slurry conditions; hence, the reactant solution must be purified after reaction by an expensive procedure to recover the catalyst.

\section{CONCLUSIONS}

Several low-loaded Pd monometallic and Pd-Ni bimetallic catalysts were prepared and evaluated in the semi-hydrogenation of 1-heptyne.

The XPS results suggest that nickel addition as a second metal to Pd catalysts modifies the electronic state of palladium leaving it more electron-deficient as nickel loading is increased.

All of the palladium catalysts presented higher selectivities to 1-heptene (c.a. 98\%) than the Lindlar catalyst (76-88\%). The addition of $\mathrm{Ni}$ as a second metal to alumina supported palladium has no influence on the selectivity to 1-heptene. The high selectivities obtained with the Pd mono and bimetallic catalysts could be attributed, at least in part, to the disappearance of the $\beta$-PdH phase. The activities of the palladium catalysts increased with the nickel content: $\mathrm{PdAl}<\mathrm{Pd}-\mathrm{Ni}_{(0.5 \%)}<\mathrm{Pd}-\mathrm{Ni}_{(1.0 \%)}$, indicating a positive synergetic effect of $\mathrm{Ni}$ over Pd. Up to $30 \%$ of 1-heptyne total conversion, $\mathrm{Pd}-\mathrm{Ni}_{(1.0 \%)}$ presented a higher conversion to 1-heptene than the classical Lindlar catalyst. The differences in activities can be attributed, at least in part, to electronic effects, due to the presence of different Pd electrondeficient species on the surface on the catalysts, as determined by XPS. However, the influence of geometrical effects and/or mixed sites cannot be neglected.

Nickel proved to be a good promoter for the palladium monometallic catalyst as it caused an increment in the total conversion without modifying the high selectivity to 1-heptene of PdAl. $\mathrm{Pd}-\mathrm{Ni}_{(1.0 \%)}$ was the most active catalyst prepared, being its selectivity to 1 -heptene higher than that obtained with the Lindlar catalyst. This bimetallic catalyst presents the advantages of low Pd loading and low cost of the nickel salt.

\section{ACKNOWLEDGMENTS}

The experimental assistance of C. Mázzaro and the financial assistance of UNL, CONICET and ANPCyT are greatly acknowledged.

\section{REFERENCES}

1. L'Argentière, P. C.; Cagnola, E. A.; Quiroga, M. E.; Liprandi, D. A.; Appl. Catal. A: Gen. 2002, 226, 253. 
2. Teschner, D.; Vass, E.; Hävecker, M.; Zafeiratos, S.; Schnörch, P.; Sauer, H.; Knop-Gericke, A.; Schlögl, R.; Chamam, M.; Wootsch, A.; Canning, A. S.; Gamman, J. J.; Jackson, S. D.; McGregor, J.; Gladden, L. F.; J. Catal. 2006, 242, 26; Kačer, P.; Kuzma, M.; Ćervenỳ, L.; Appl. Catal. A: Gen. 2004, 259, 179; Choudary, B. M.; Lakshmi Kantam, M.; Mahender Reddy, N.; Koteswara Rao, K.; Haritha, Y.; Bhaskar, V.; Figueras, F.; Tuel, A.; Appl. Catal. A: Gen. 1999, 181, 139.

3. Nishimura, S.; Handbook of Heterogeneous Catalytic Hydrogenation for Organic Synthesis, John Wiley \& Sons, Inc.: Canada, 2001.

4. Chen, B.; Dingerdissen, U.; Krauter, J. G. E.; Lansink Rotgerink, H. G. J.; Möbus, K.; Ostgard, D. J.; Panster, P.; Riermeier, T. H.; Seebald, S.; Tacke, T.; Trauthwein, H.; Appl. Catal. A: Gen. 2005, 280,17.

5. Lindlar, H.; Dubuis, R.; Org. Synth. 1966, 46, 89.

6. Abelló, S.; Verboekend, D.; Bridier, B.; Pérez-Ramírez, J.; J. Catal. 2008, 259, 85.

7. Alonso, F.; Osante, I.; Yus, M.; Adv. Synth. Catal. 2006, 348, 305.

8. Dhakshinamoorthy, A.; Pitchumani, K.; Tetrahed. Lett. 2008, 49, 1818.

9. Zhao, Z.-F.; Wu, Z.-J.; Zhoy, L.-X.; Zhang, M.-H.; Li, W.; Tao, K.-Y.; Catal. Commun. 2008, 9, 2191.

10. Choi, J.; Yoon, N. M.; Tetrahed. Lett. 1996, 37, 1057.

11. Huang, W.; McCormick, J. R.; Lobo, R. F.; Chen, J. G.; J. Catal. 2007, 246, 40; Huang, W.; Pyrz, W.; Lobo, R. F.; Chen, J.G.; Appl. Catal. A: Gen. 2007, 333, 254.

12. Zhang, Q.; Li, J.; Liu, X.; Zhu, Q.; Appl. Catal. A: Gen. 2000, 197, 221.

13. Sárkány, A.; Horváth, A.; Beck, A.; App. Catal. A: Gen. 2002, 229, 117.

14. Spee, M. P. R.; Boersma, J.; Meijer, M. D.; Slagt, M. Q.; van Koten, G.; Geus, J. W.; J. Org. Chem. 2001, 66, 1647.

15. Sárkány, A.; Geszti, O.; Sáfrán, G.; Appl. Catal. A: Gen. 2008, 350, 157; Hamilton, C. A.; Jackson, S. D.; Kelly, G. J.; Spence, R.; de Bruin, D.; Appl. Catal. A: Gen. 2002, 237, 201.

16. Jung, A.; Jess, A.; Schubert, T.; Schütz, W.; Appl. Catal. A: Gen. 2008 , 362, 95; Papp, A.; Molnár, Á.; Mastalir, Á.; Appl. Catal. A: Gen. 2005, 289, 256; Mastalir, Á.; Király, Z.; J. Catal. 2003, 220, 372; Mastalir, Á.; Király, Z.; Szöllösi, Gy.; Bartók, M.; Appl. Catal. A: Gen. 2001, 213, 133; Mastalir, Á.; Király, Z.; Berger, F.; Appl. Catal A: Gen. 2004, 269, 161.

17. Lederhos, C.; L'Argentière, P. C.; Fígoli, N. S.; Ind. Eng. Chem. Res. 2005, 44, 1752; Lederhos, C.; L'Argentière, P. C.; Coloma-Pascual, F.; Fígoli, N. S.; Catal. Lett. 2006, 110, 23.

18. Mudakavi, J. R.; Kamakrishna, T. V.; J. Ind. Inst. Sci. 1979, 61, 151; Kenigsburg, M.; Stone, I.; Anal. Chem. 1955, 27, 1339.

19. Benson, J. E.; Hwang, H. S.; Boudart, M. ; J. Catal. 1973, 30, 146.

20. Roma, M. N. S. C.; Cunha, D. S.; Cruz, G. M.; Cobo, A. J. G.; Braz. J. Chem. Eng. 2000, 17, 4.
21. Wang, C.-B.; Lin, H.-K.; Ho, C.-M.; J. Molec. Catal. A: Chem. 2002, 180, 285.

22. Quincoces, C. E.; Dicundo, S.; Alvarez, A. M.; González, M. G.; Mat. Lett. 2001, 50, 21; Pompeo, F.; Nichio, N. N.; Souza, M. M. V. M.; Cesar, D. V. M.; Ferretti, O. A.; Schmal, M.; Appl. Catal. A: Gen. 2007, 316, 175.

23. Borade, R.; Sayari, A.; Kaliaguine, S.; J. Phys. Chem. 1990, 94, 5989.

24. Hu, S.; Chen, Y.; J. Chin. Chem. Engrs. 1998, 29, 381.

25. Liprandi, D. A.; Quiroga, M. E.; Cagnola, E. A.; L'Argentière, P. C.; Ind. Eng. Chem. Res. 2002, 41, 4906.

26. Niklasson, C.; Anderson, B.; Schoon, N.; Ind. Eng. Chem. Res. 1987, $26,1459$.

27. L'Argentière, P. C.; Cañón, M. M.; Fígoli, N. S.; Ferrón, J.; Appl. Surf. Sci. 1993, 68, 41.

28. http://srdata.nist.gov/xps/, accessed in May 2009.

29. Dantas Ramos, A. L.; Alves, P. D. S.; Aranda, D. A. G.; Schmal, M.; Appl. Catal. A: Gen. 2004, 277, 71.

30. Hillebrecht, F. U.; Fuggle, J. C.; Bennett, P. A.; Zolnierek, Z.; Phys. Rev. B 1982, 27, 2179.

31. Barrio, V. L.; Arias, P. L.; Cambra, M. B.; Güemez, M. B.; Pawelec, B.; Fierro, J. L. C. Catal. Commun. 2004, 5, 173.

32. Noronha, F. B.; Schmal, M.; Primet, M.; Frety, R.; Appl. Catal. 1991, 78,125 .

33. Noronha, F. B.: Aranda, D. A. G.; Ordine, A. P.; Schmal, M.; Catal. Today 2000, 57, 275; Kennedy, D. R.; Webb, G.; Jackson, S. D.; Lennon, D.; Appl. Catal. A: Gen. 2004, 259, 109.

34. Chen, G.; Chou, W.-T.; Yeh, C.-T.; Appl. Catal. 1983, 8, 389; Gaspar, A. B.; Dieguez, L. C.; Appl. Catal. A: Gen. 2001, 201, 241.

35. Cardenas-Lizana, F.; Gómez-Quero, S.; Keane, M. A.; Appl. Catal. A: Gen. 2008, 334, 199.

36. Hoffer, B. W.; Dick van Langeveld, A.; Janssens, J. P.; Bonne, R. L. C.; Lok, C. M.; Moulijn, J. A.; J. Catal. 2000, 192, 432.

37. Kim, P.; Kim, H.; Joo, J. B.; Kim, W.; Song, I. K.; Yi, J.; J. Molec. Catal. A: Chem. 2006, 256, 178.

38. Li, G.; Hu, L.; Hill, J. M.; Appl. Catal. A: Gen. 2006, 301, 16.

39. Hou, Z.; Yokota, O.; Tanaka, T.; Yashima, T.; Appl. Catal. A: Gen. 2003 , 253,381 .

40. Mukainakano, Y.; Yoshida, K.; Okumura, K.; Kunimori, K.; Tomishige, K.; Catal. Today 2008, 138, 101.

41. Nijhuis, T. A.; van Koten, G.; Moulijn, J. A.; Appl. Catal. A: Gen. 2003, 238, 259.

42. Coq, B.; Figueras, F.; J. Mol. Catal A: Chem 2001, 173, 117.

43. Carturan, G.; Facchin, G.; Cocco, G.; Enzo, S.; Navazio, G.; J. Catal. 1982, 76, 405. 